\title{
Malaria hospitalisation in East Africa: age, phenotype and transmission intensity
}

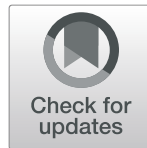

\begin{abstract}
Alice Kamau ${ }^{1 *} \mathbb{D}$, Robert S. Paton ${ }^{2}$, Samuel Akech ${ }^{1}$, Arthur Mpimbaza ${ }^{3}$, Cynthia Khazenzi ${ }^{1}$, Morris Ogero', Eda Mumo', Victor A. Alegana', Ambrose Agweyu', Neema Mturi', Shebe Mohammed', Godfrey Bigogo ${ }^{5}$, Allan Audi ${ }^{5}$, James Kapisi ${ }^{6}$, Asadu Sserwanga ${ }^{6}$, Jane F. Namuganga ${ }^{6}$, Simon Kariuki ${ }^{5}$, Nancy A. Otieno ${ }^{5}$, Bryan O. Nyawanda ${ }^{5}$, Ally Olotu', Nahya Salim7, Thabit Athuman7, Salim Abdulla ${ }^{7}$, Amina F. Mohamed ${ }^{8,9}$, George Mtove $^{10}$, Hugh Reyburn ${ }^{9}$, Sunetra Gupta ${ }^{2}$, José Lourenço ${ }^{2}$, Philip Bejon ${ }^{4,11}$ and Robert W. Snow ${ }^{1,11}$
\end{abstract}

\begin{abstract}
Background: Understanding the age patterns of disease is necessary to target interventions to maximise costeffective impact. New malaria chemoprevention and vaccine initiatives target young children attending routine immunisation services. Here we explore the relationships between age and severity of malaria hospitalisation versus malaria transmission intensity.

Methods: Clinical data from 21 surveillance hospitals in East Africa were reviewed. Malaria admissions aged 1 month to 14 years from discrete administrative areas since 2006 were identified. Each site-time period was matched to a model estimated community-based age-corrected parasite prevalence to provide predictions of prevalence in childhood (PfPR $2-10)$. Admission with all-cause malaria, severe malaria anaemia (SMA), respiratory distress (RD) and cerebral malaria (CM) were analysed as means and predicted probabilities from Bayesian generalised mixed models.

Results: 52,684 malaria admissions aged 1 month to 14 years were described at 21 hospitals from 49 site-time locations where $P f \mathrm{PR}_{2-10}$ varied from $<1$ to $48.7 \%$. Twelve site-time periods were described as low transmission $\left(\right.$ PfPR $_{2-10}<5 \%$ ), five low-moderate transmission (PfPR $2-10$ 5-9\%), 20 moderate transmission (PfPR $\left.2-1010-29 \%\right)$ and 12 high transmission (PfPR $2-10 \geq 30 \%)$. The majority of malaria admissions were below 5 years of age (69-85\%) and rare among children aged 10-14 years $(0.7-5.4 \%)$ across all transmission settings. The mean age of all-cause malaria hospitalisation was 49.5 months $(95 \% \mathrm{Cl} 45.1,55.4)$ under low transmission compared with 34.1 months (95\% Cl $30.4,38.3)$ at high transmission, with similar trends for each severe malaria phenotype. CM presented among older children at a mean of 48.7 months compared with 39.0 months and 33.7 months for SMA and RD, respectively. In moderate and high transmission settings, 34\% and 42\% of the children were aged between 2 and 23 months and so within the age range targeted by chemoprevention or vaccines.
\end{abstract}

Conclusions: Targeting chemoprevention or vaccination programmes to areas where community-based parasite prevalence is $\geq 10 \%$ is likely to match the age ranges covered by interventions (e.g. intermittent presumptive treatment in infancy to children aged 2-23 months and current vaccine age eligibility and duration of efficacy) and the age ranges of highest disease burden.

Keywords: Malaria, Age pattern, Parasite prevalence, Severe malaria, Anaemia, Cerebral malaria

\footnotetext{
* Correspondence: akamau@kemri-wellcome.org

'Kenya Medical Research Institute (KEMRI) - Wellcome Trust Research

Programme, Nairobi, Kenya

Full list of author information is available at the end of the article
}

C The Author(s). 2022 Open Access This article is licensed under a Creative Commons Attribution 4.0 International License, which permits use, sharing, adaptation, distribution and reproduction in any medium or format, as long as you give appropriate credit to the original author(s) and the source, provide a link to the Creative Commons licence, and indicate if changes were made. The images or other third party material in this article are included in the article's Creative Commons licence, unless indicated otherwise in a credit line to the material. If material is not included in the article's Creative Commons licence and your intended use is not permitted by statutory regulation or exceeds the permitted use, you will need to obtain permission directly from the copyright holder. To view a copy of this licence, visit http://creativecommons.org/licenses/by/4.0/. The Creative Commons Public Domain Dedication waiver (http://creativecommons.org/publicdomain/zero/1.0/) applies to the data made available in this article, unless otherwise stated in a credit line to the data. 


\section{Background}

Malaria is a vector-borne disease endemic to large parts of sub-Saharan Africa (SSA), where the predominant parasite that infects humans is Plasmodium falciparum. Exposure to bites from infected mosquitoes results in human infection which can be asymptomatic or develop into mild symptoms including fever, and a minority of infections progress to severe complications that might result in death $[1,2]$. Immunity is dependent on the frequency of parasite exposure from birth and is thought to manifest at different periods in an individual's lifetime for severe life-threatening disease, mild, self-limiting disease and asymptomatic blood-stage infection [3, 4]. The relationship between natural parasite exposure, immunity and the age-specific patterns of severe disease and death has been inadequately defined $[1,5,6]$ but remains critical to understanding targeted intervention.

Reliable information on the age-specific patterns of malaria mortality are difficult to obtain in SSA [7] where most deaths occur in the community without medical or laboratory confirmation. Cause-of-death, therefore, depends entirely on responses from verbal autopsies (VA) administered to bereaved relatives [8]. Attribution of malaria as a cause of death using VA largely depends on reported fever during the terminal illness which lacks both sensitivity and specificity [9-11]. An alternative source of information is severe, life-threatening malaria which can be identified by clinical assessment [12-15]. Whilst not all severe malaria episodes reach the hospital, those that do provide important insights into the epidemiology of the life-threatening disease in the communities served by these hospitals.

Community-based parasite prevalence continues to be one important measure of malaria used in the epidemiological sub-national stratification for intervention decision-making [16, 17]. The Plasmodium falciparum parasite prevalence is measured in households or schools among asymptomatic individuals providing a quantity of the intensity of malaria transmission in a given locality and traditionally standardised to a single age group 210 years $\left(\right.$ PfPR $\left._{2-10}\right)$ [17-20].

Twenty years ago, hospitalised malaria events were used to provide epidemiological descriptions of severe malaria across different malaria transmission ecologies in SSA [21-31] during an era of failing first-line treatment and widespread increases in parasite prevalence [17]. The relationship between community parasite prevalence and severe malaria outcomes continues to be based on hospital data generated over 20 years ago [3235]. New data are needed to guide the appropriate age ranges for novel personal protection interventions linked to the expanded programme of immunisation (EPI). Intermittent presumptive treatment in infancy (IPTi) is currently targeted at children aged 2-11 months [36, 37] and RTS,S/R21 vaccination is targeted at children aged 5-24 months with protection estimated at around 36month duration following a fourth dose [38-40]. Seasonal malaria chemoprevention (SMC) focuses predominantly on providing drugs to children below 5 years across seasonal transmission sites of the Sahel [41] and recently combined with RTS,S vaccination in this age group [42, 43].

The absence of contemporary empirical data on the age patterns of malaria mortality and severe disease across the range of transmission settings that characterise Africa today limits our ability to target novel interventions to maximise impact. Here we present a description of age and clinical epidemiology of malaria hospitalisation among children 1 month to 14 years of age presenting to 21 hospitals in East Africa that serve communities of varying parasite prevalence common to the sub-region since the introduction of artemisininbased combination therapy and expanded vector control.

\section{Methods}

\section{Study site selection}

A secondary analysis was performed on data from hospitals that maintained continuous paediatric ward surveillance including malaria parasitology, purposively designed case record forms and documentation of patient residential addresses between 2006 and 2021. These were sentinel hospital sites for randomised controlled trials or sites for intensive clinical surveillance (Additional file 1: Fig. S1 \& Additional file 2: Table S1) [44-66]. Twenty-one hospitals were included, which supported emergency care from 36 administrative areas and in over 49 separate hospital-site-time periods across East Africa (Additional file 1: Fig. S1 \& Additional file 2: Table S1). Administrative areas were defined proximal to each hospital and represented as sub-counties in Kenya, councils in Tanzania and districts in Uganda. Address details of patients were reviewed to identify those from specific administrative areas. Site data covering more than one period were analysed as independent data items given interruptions in surveillance (Uganda) or reasoned temporal divisions in the data based on scaled introduction of free insecticide-treated nets (Kilifi and Rarieda, Kenya) or indoor-residual house-spraying (Tororo, Uganda), hereafter referred as site-time periods.

\section{Measures of transmission intensity}

Parasite prevalence among residents of areas served by the 21 hospitals provided a categorical quantity of malaria exposure in each location. We have used temporally and spatially (sub-county, council or district) matched predicted estimates of Plasmodium falciparum parasite prevalence in children aged $2-10$ years $\left(P f \mathrm{PR}_{2-10}\right)$, generated from Bayesian model-based spatiotemporal 
geostatistical analysis of $>18,000$ empirical geocoded point surveys undertaken across East Africa since 2010 [64]. In brief, the Bayesian hierarchical space-time model was implemented through a stochastic partial differential equations approach using the Integrated Nested Laplace Approximations in $\mathrm{R}$ adjusting for climatic and ecological covariates priors to improve predictions of $P f \mathrm{PR}_{2-10}$ at unsampled locations. Data were corrected to standardise surveys using rapid diagnostic tests (RDT) to microscopy using a Bayesian probit regression [67]. Computation used the full spatial and temporal range of the data and aimed at estimating the continuous posterior median of $P f \mathrm{PR}_{2-10}$ at $1 \times 1 \mathrm{~km}$ spatial resolutions for each year from 2010 and aggregated to the spatial extents of each administrative, hospital polygon and over the surveillance period of each hospital-catchment period. For sites pre-2010, similar, published geostatistical modelled approaches were used to obtain predicted $P f \mathrm{PR}_{2-10}$ but these models did not include covariate priors nor correct RDT to microscopy in Kenya [65] and Tanzania [66]. We have elected to use categorical definitions of parasite prevalence used by national malaria programmes in East Africa to select interventions most likely to provide optimised, efficient use of malaria prevention strategies sub-nationally $[65,66,68,69]$ : low transmission intensity settings for $P f \mathrm{PR}_{2-10}<5 \%$, lowmoderate for $P f \mathrm{PR}_{2-10} 5-9 \%$, moderate for $P f \mathrm{PR}_{2-10} 10-$ $29 \%$, and high for $P f \mathrm{PR}_{2-10} \geq 30 \%$.

\section{Malaria case definitions}

Children were included in the analysis if they were aged 1 month to 14 years, were resident in selected administrative areas and had evidence of laboratory-confirmed malaria infection on admission and a final discharge diagnosis of malaria following review of all available clinical and laboratory findings by hospital clinicians. At admission, information was documented for each patient on severe disease phenotypes including measured levels of consciousness, respiratory distress and anaemia (Additional file 2: Table S2) [15, 70, 71]. Cerebral malaria $(\mathrm{CM})$ was defined at different sites using either the Blantyre Coma Score (BCS) < 3 (10 site-time periods) or documented neurological responsiveness based on the Alert, response to Voice, response to Pain, or Unconscious (AVPU) scale (39 site-time periods), where unconscious was regarded as equivalent to a BCS $<3$. Severe malaria anaemia (SMA) was defined among children who had a haemoglobin $(\mathrm{HB})<5 \mathrm{~g} / \mathrm{dl}$. However, haemoglobin concentrations were not available among all admissions at all sites (Additional file 2: Table S2). Where $\mathrm{HB}$ was not available, information on whether clinicians ordered a blood transfusion was used as a secondary measure of SMA. SMA was defined based on HB among 11,671 admissions where a blood sample was taken. For a further 9,869 admissions where HB was not reported, blood transfusion ordered was indicative of SMA [72]. Respiratory distress (RD) was defined as observed deep breathing, a proxy for acidotic breathing, available at 43 sites. Data to assess other criteria for severe malaria (e.g. blood glucose or renal function) were not available and some children admitted for malaria may not have formally met the criteria for severe malaria. We included "all cause malaria admissions" as a group that would include both these groups as well as SMA, CM and RD. We included 21,540/46,076 (46.7\%) of the malaria admissions from 43 site-time periods, where information on all three severe malaria phenotypes (SMA, RD and CM) were documented to demonstrate the overlap in these three phenotypes.

\section{Statistical analyses}

A Bayesian generalised linear mixed model (GLMM) was developed to analyse how the age distribution of allcause malaria admissions changed with parasite prevalence. Age was assumed to follow a Gamma distribution, with the average of this distribution modelled with a log-linear function of parasite prevalence. The random effect accounted for site-time deviations from the predicted mean. We compared a model with and without the log-linear effect of parasite prevalence to determine the statistical support for the inclusion of this term in the model using the widely applicable information criterion, WAIC [73]. Additionally, the age distribution of the three phenotypes (SMA, RD and CM) was assessed using a similar model form but included an additional random effect term to account for phenotype-specific site-time deviations. Models were fit in the Bayesian inference package Stan version 2.21.0 [74] interfaced through the statistical software $\mathrm{R}$ version 4.1.0 [75]. Six chains were run until all parameters achieved convergence $(R \leq 1.01)$. Uncertainty was reported as $95 \%$ credible intervals (CIs). A detailed description of the model structure and selection procedure can be found in Additional file 3.

In the pilot implementation study in Ghana, Malawi and Kenya, the first dose of RTS,S vaccine is recommended in children aged 5-6 months, subsequent doses 2 and 3 given at respective infant EPI schedules and a 4 th dose at 22-24 months [76]. IPTi is recommended to begin at $8-10$ weeks with continued administration at repeated EPI attendances until the first birthday with at least 1 month between doses and up to 4 doses in the first year of life [36]. Additional studies have shown the efficacy of IPTi with protection age windows up to 1524 months of life $[77,78]$. To estimate the probability of all-cause malaria admission and the three phenotypes (SMA, RD and CM) occurring within the age groups 211 months and 2-23 months under different levels of 
transmission, the cumulative probability function of the Gamma distribution of the best fitting model was used. Protection from vaccines post-24 months and the possibilities of extending chemoprevention and vaccines up to 59 months of age were also considered.

\section{Results}

A total of 52,684 malaria admissions were documented at 21 hospitals covering 1,712 months of observation between 2006 and 2021. All children had a positive malaria slide, a primary discharge diagnosis of malaria, age documented and residential address identified. Forty-nine hospital site-time periods were spatially and temporally matched to the predicted $P f \mathrm{PR}_{2-10}$ (Additional file 2: Table S1). The 49 sitetime locations were characterised by a range of vector control approaches and coverage levels (Additional file 2: Table S1) and covered predicted malaria transmission conditions from $<1 \% P f R_{2-10}$ in Uganda and Kenya to the highest predicted transmission intensity described at Kisumu West 2015-18, Gem 2010-14, Alego-usonga 2010-14, Tororo 2012-15 and Apac 2017-18 where PfPR $2-10$ exceeded 40\% (Additional file 2: Table S1). No site-time locations covered contemporary transmission where predicted $P f \mathrm{PR}_{2-10}$ was $\geq 50 \%$. Twelve site-time data series were described as low transmission $(<5 \%$ PfPR $2-10)$, five were defined as lowmoderate transmission (5-9\% PfPR $2-10), 20$ were moderate transmission (10-29\% PfPR $2-10)$ and 12 were defined as high transmission $\left(\geq 30 \% P f \mathrm{PR}_{2-10}\right)$. When admissions were adjusted for the number of months of surveillance per transmission category, malaria hospital admission burdens were considerably lower in the low and low-to-moderate parasite transmission intensity settings compared to moderate and high transmission settings (Fig. 1A).

Including the effect of parasite prevalence in the age distribution model was supported by GLMM model selection (WAIC $=2.6)$ and the model fit for the individual site-time periods is shown in Additional file 1: Fig. S2. The modelled age distributions of all-cause malaria admission for each of the four discrete categories of $P f \mathrm{PR}_{2-10}$ are shown in Fig. 1B. In addition, the modelled relationship between parasite prevalence and properties relating to the age distribution of malaria admissions are presented (Fig. 2). The average age of admission as predicted by the GLMM decreased as parasite prevalence increased (Figs. 1B and 2A), ranging from 49.5

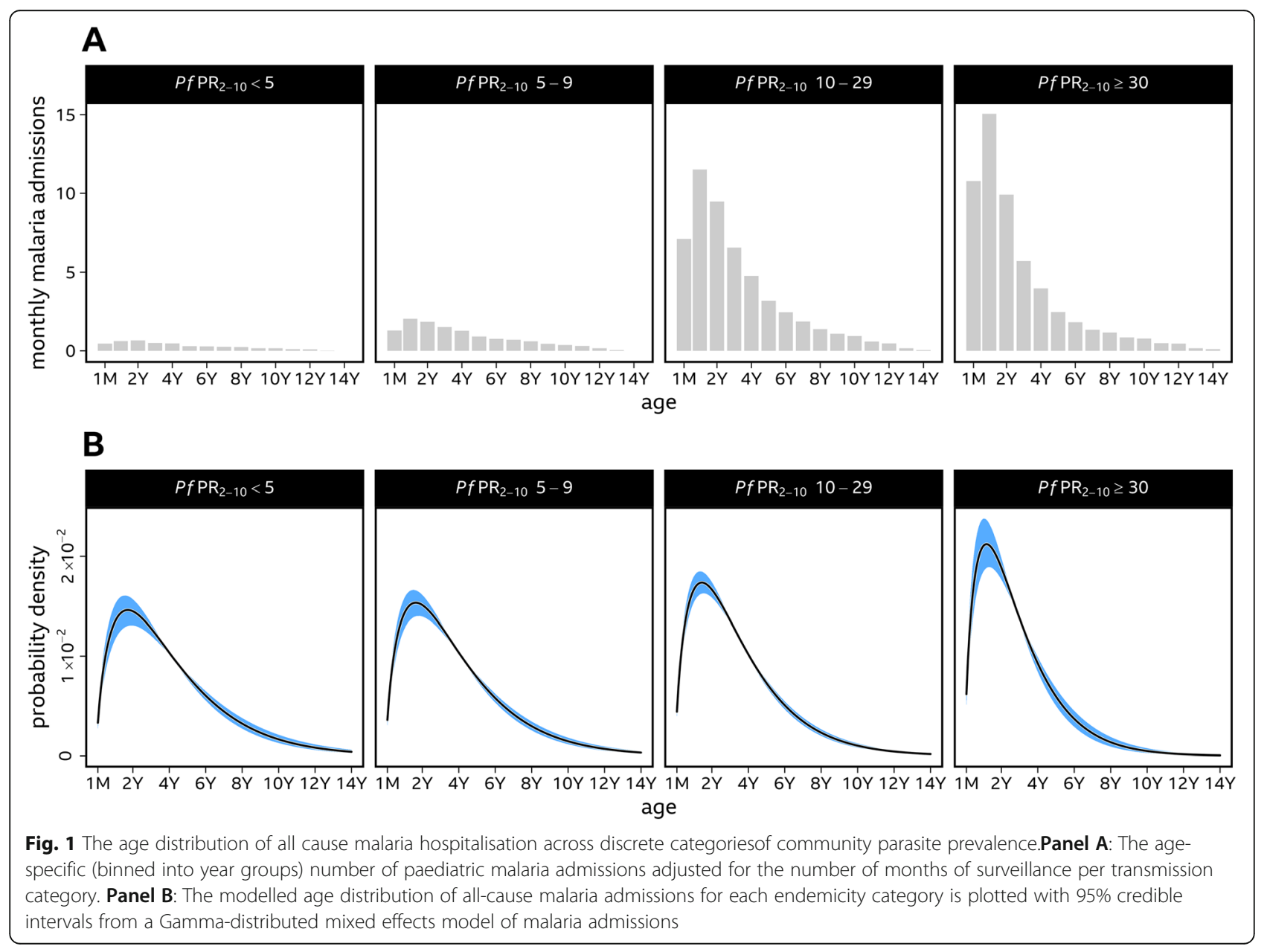



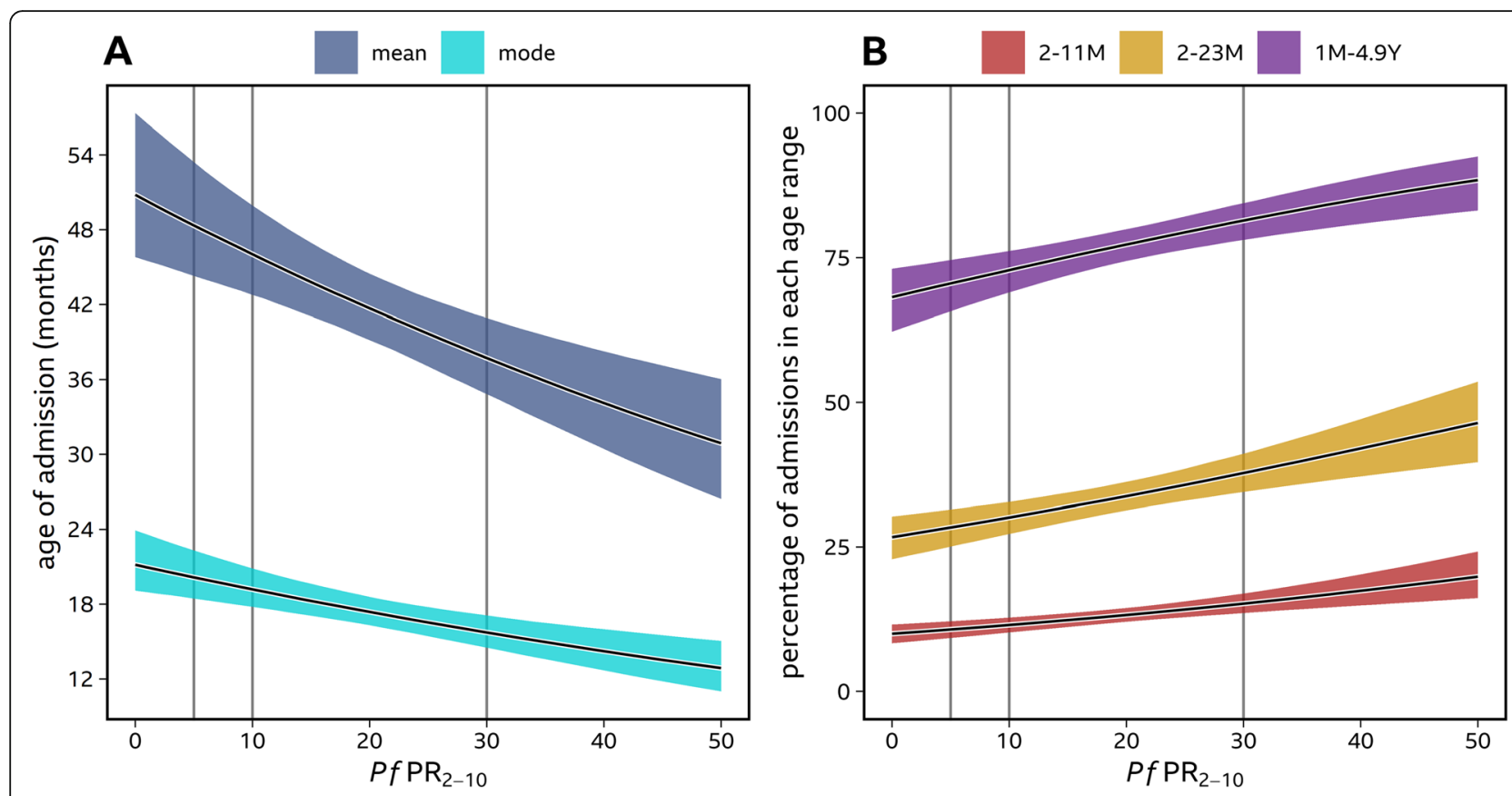

Fig. 2 The modelled effect of parasite prevalence on the age characteristics of all-causemalaria admissions. Panel $\mathbf{A}$, the change in the mean and most frequent age of admission is shown.Panel B gives effect of parasite prevalence on the probability of being admitted in one of three discrete age categories as calculated by integrating the Gamma density function across the age range

months $\left(95 \%\right.$ CI 45.1, 55.4) at low transmission $\left(<5 \% \mathrm{PfPR}_{2-}\right.$ 10) to 34.1 months $(95 \%$ CI 30.4, 38.3) in the highest transmission classification $(\geq 30 \%$ PfPR $2-10)$.

Across all transmission settings, admissions were concentrated in children under 5 years old (Figs. 1B and 2B), ranging from $69.4 \%(95 \%$ CI 64.0, 73.8) in the lowest transmission category $\left(P f \mathrm{PR}_{2-10}<5 \%\right)$ to $85.2 \%(95 \% \mathrm{CI}$ $80.9,88.9)$ in the highest transmission category $\left(P f \mathrm{PR}_{2-10} \geq\right.$ $30 \%$ as predicted from the cumulative probability function of the Gamma distribution. Furthermore, across all transmission settings, the probability of admitted children being aged 10 years and above was very low at $5.4 \%(95 \%$ CI $3.7,7.9)$ in the lowest transmission category and $0.7 \%(95 \% \mathrm{CI} 0.1,1.6)$ in the highest transmission category (Fig. 1B). Under low transmission, $10.3 \%$ (95\% CI 8.8, 11.8) of admitted children were predicted to be aged 2-11 months and $27.5 \%$ (95\% CI $24.0,30.8)$ to be children aged 2-23 months. In the lowmoderate, the corresponding probabilities of admission were $11.1 \%$ (95\% CI 9.7, 12.4) for $2-11$ months and $29.2 \%$ (95\% CI 26.2, 32.1) for $2-23$ months. At levels of moderate transmission intensity, the probability of admitted children being aged 2-11 months was $13.2 \%$ (95\% CI 12.1, 14.4) and 33.8\% (95\% CI 31.3, 36.2) for the age range 2-23 months. These values rose to $17.4 \%(95 \%$ CI 14.9, 20.2) and $42.0 \%$ (95\% CI $37.2,47.1)$, respectively, in the highest transmission intensity of $P f \mathrm{PR}_{2-10} \geq 30 \%$.

Across the four discrete categories of $P f \mathrm{PR}_{2-10}$, SMA was the most common phenotype, accounting for $74.3 \%$

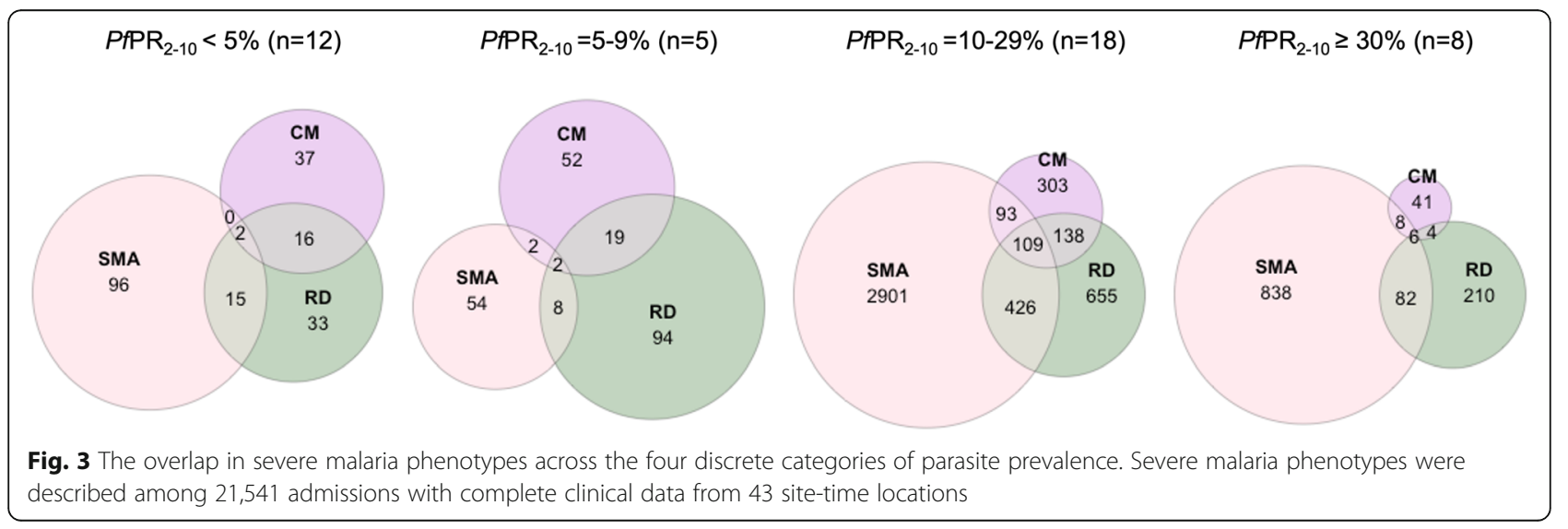


(4642/6244) of all severe malaria admissions and in $76.3 \%$ and $78.6 \%$ in the moderate and high transmission settings, respectively (Fig. 3). RD was described in 1819 admissions and accounted for $29.1 \%$ of all severe malaria admissions across the combined transmission settings (Fig. 3). CM was described among 832 (13.3\%) severe malaria admissions and was a much rarer event compared to SMA and RD; however, CM was relatively more common in the two lowest transmission categories albeit rare in absolute terms across all settings (Fig. 3).

The age patterns of the three severe malaria phenotypes showed similar trends in decreasing mean ages with increasing intensity of transmission classification, despite differences in the mean ages between phenotypes (Table 1). The mean age of SMA cases decreased from 44.6 months $(95 \%$ CI 39.5, 50.6) in low transmission

Table 1 Characteristics of malaria admissions (1 month-14 years) by predicted PfPR $2-10$ categories. Further details for each site-time period are provided in Additional file 2: Table S2

\begin{tabular}{|c|c|c|c|c|c|}
\hline Indicators & $\mathrm{PfPR}_{2-10}<5 \%$ & $\mathrm{PfPR}_{2-10} 5-9 \%$ & $\mathrm{PfPR}_{2-10} 10-29 \%$ & $P P_{2-10} \geq 30 \%$ & Overall \\
\hline No. of sites (date range) & $12(2006-2021)$ & $5(2012-2021)$ & $20(2006-2021)$ & $12(2006-2021)$ & $49(2006-2021)$ \\
\hline Site-time in months & 447 & 158 & 736 & 371 & 1712 \\
\hline All-cause malaria & 1431 & 1540 & 31885 & 17828 & 52684 \\
\hline Mean age months $(95 \% C l)$ & $49.5(45.1,55.4)$ & $47.2(43.5,51.6)$ & $41.7(39.2,44.5)$ & $34.1(30.4,38.3)$ & $42.1(39.1,45.2)$ \\
\hline \multicolumn{6}{|l|}{ Age-specific probabilities (\%) } \\
\hline $2-11$ age in months $(95 \% \mathrm{Cl})$ & $10.3(8.8,11.8)$ & $11.1(9.7,12.4)$ & $13.2(12.1,14.4)$ & $17.4(14.9,20.2)$ & $13.1(11.8,14.5)$ \\
\hline $2-23$ age in months $(95 \% \mathrm{Cl})$ & $27.5(24.0,30.8)$ & $29.2(26.2,32.1)$ & $33.8(31.3,36.2)$ & $42.0(37.2,47.1)$ & $33.4(30.8,36.3)$ \\
\hline Under 5 years $(95 \% C l)$ & $69.4(64.0,73.8)$ & $71.7(67.4,75.4)$ & $77.3(74.4,79.9)$ & $85.2(80.9,88.9)$ & $76.9(73.7,79.9)$ \\
\hline $\begin{array}{l}\text { Mortality }(95 \% C l) ; \uparrow \\
n / N \text { (no. of sites) }\end{array}$ & $\begin{array}{l}3.2 \%(2.3,4.3) \\
45 / 1406(12)\end{array}$ & $\begin{array}{l}2.0 \%(1.4,2.9) \\
31 / 1518(5)\end{array}$ & $\begin{array}{l}1.8 \%(1.7,2.0) \\
532 / 28774(20)\end{array}$ & $\begin{array}{l}1.0 \%(0.9,1.2) \\
166 / 16672(12)\end{array}$ & $\begin{array}{l}1.5 \%(1.4,1.7) \\
744 / 48370(49)\end{array}$ \\
\hline $\begin{array}{l}\text { Severe malaria anaemia* (\%) } \\
n / N \text { (no. of sites) }\end{array}$ & $\begin{array}{l}8.6 \% \\
115 / 1341(12)\end{array}$ & $\begin{array}{l}5.4 \% \\
66 / 1229(5)\end{array}$ & $\begin{array}{l}27.0 \% \\
3798 / 14088(20)\end{array}$ & $\begin{array}{l}14.8 \% \\
1281 / 8663(12)\end{array}$ & $\begin{array}{l}20.8 \% \\
5260 / 25321(49)\end{array}$ \\
\hline Mean age months $(95 \% C l)$ & $44.6(39.5,50.6)$ & $42.5(38.1,47.7)$ & $37.7(34.2,41.5)$ & $31.1(27.4,35.1)$ & $39.0(35.3,42.7)$ \\
\hline \multicolumn{6}{|l|}{ Age-specific probabilities (\%) } \\
\hline $2-11$ age in months $(95 \% \mathrm{Cl})$ & $11.5(9.4,13.7)$ & $12.3(10.4,14.5)$ & $14.6(12.7,16.8)$ & $19.1(16.1,22.6)$ & $14.0(12.2,16.2)$ \\
\hline $2-23$ age in months $(95 \% \mathrm{Cl})$ & $30.7(26.2,35.4)$ & $32.5(28.2,36.9)$ & $37.4(33.3,41.6)$ & $45.9(40.4,51.7)$ & $36.0(32.3,40.2)$ \\
\hline Under 5 years $(95 \% C l)$ & $74.5(68.4,79.8)$ & $76.7(71.3,81.3)$ & $81.8(77.7,85.5)$ & $88.6(84.5,92.0)$ & $80.3(76.4,84.2)$ \\
\hline $\begin{array}{l}\text { Mortality }(95 \% C l) ; \uparrow \\
n / N \text { (no. of sites) }\end{array}$ & $\begin{array}{l}8.3 \%(3.9,15.2) \\
9 / 108(12)\end{array}$ & $\begin{array}{l}9.5 \%(3.6,19.6) \\
6 / 63(5)\end{array}$ & $\begin{array}{l}5.3 \%(4.5,6.1) \\
170 / 3209(20)\end{array}$ & $\begin{array}{l}4.2 \%(3.1,5.5) \\
49 / 1169(12)\end{array}$ & $\begin{array}{l}5.1 \%(4.5,5.8) \\
234 / 4549(49)\end{array}$ \\
\hline $\begin{array}{l}\text { Respiratory distress (\%) } \\
n / N \text { (no. of sites) }\end{array}$ & $\begin{array}{l}6.0 \% \\
85 / 1426(12)\end{array}$ & $\begin{array}{l}10.6 \% \\
162 / 1531(5)\end{array}$ & $\begin{array}{l}9.5 \% \\
2740 / 28808(18)\end{array}$ & $\begin{array}{l}4.8 \% \\
615 / 12884(8)\end{array}$ & $\begin{array}{l}8.1 \% \\
3602 / 44649(43)\end{array}$ \\
\hline Mean age months $(95 \% \mathrm{Cl})$ & $40.1(35.2,46.0)$ & $38.1(33.9,43.4)$ & $33.8(30.3,38.2)$ & $27.9(24.2,32.4)$ & $33.7(30.3,37.1)$ \\
\hline \multicolumn{6}{|l|}{ Age-specific probabilities (\%) } \\
\hline $2-11$ age in months $(95 \% \mathrm{Cl})$ & $13.4(10.9,16.1)$ & $14.4(11.9,17.0)$ & $17.0(14.3,19.8)$ & $22.1(18.1,26.4)$ & $17.2(15.0,19.8)$ \\
\hline $2-23$ age in months $(95 \% \mathrm{Cl})$ & $34.8(29.5,40.3)$ & $36.8(31.6,42.0)$ & $42.0(36.8,47.0)$ & $50.9(44.0,57.7)$ & $42.2(38.0,47.0)$ \\
\hline Under 5 years $(95 \% C l)$ & $79.2(73.0,84.4)$ & $81.2(75.7,85.8)$ & $85.8(81.2,89.3)$ & $91.6(87.2,94.6)$ & $85.9(82.3,89.3)$ \\
\hline $\begin{array}{l}\text { Mortality }(95 \% \mathrm{Cl}) ; \uparrow \\
n / N \text { (no. of sites) }\end{array}$ & $\begin{array}{l}12.9 \%(6.6,22.0) \\
11 / 85(11)\end{array}$ & $\begin{array}{l}6.3 \%(3.1,11.3) \\
10 / 158(3)\end{array}$ & $\begin{array}{l}6.1 \%(5.1,7.1) \\
147 / 2427(17)\end{array}$ & $\begin{array}{l}5.8 \%(4.0,8.1) \\
32 / 553(8)\end{array}$ & $\begin{array}{l}6.2 \%(5.4,7.1) \\
200 / 3223(39)\end{array}$ \\
\hline $\begin{array}{l}\text { Cerebral malaria (\%) } \\
n / N \text { (no. of sites) }\end{array}$ & $\begin{array}{l}4.2 \% \\
60 / 1423(12)\end{array}$ & $\begin{array}{l}5.3 \% \\
81 / 1530(5)\end{array}$ & $\begin{array}{l}3.1 \% \\
945 / 30494(20)\end{array}$ & $\begin{array}{l}0.6 \% \\
105 / 17052(12)\end{array}$ & $\begin{array}{l}2.4 \% \\
1191 / 50499(49)\end{array}$ \\
\hline Mean age months $(95 \% \mathrm{Cl})$ & $56.2(49.0,64.9)$ & $53.5(47.1,61.1)$ & $47.4(42.1,53.5)$ & $39.1(33.9,45.1)$ & $48.7(43.3,54.1)$ \\
\hline \multicolumn{6}{|l|}{ Age-specific probabilities (\%) } \\
\hline $2-11$ age in months $(95 \% \mathrm{Cl})$ & $8.1(6.4,10.0)$ & $8.7(7.0,10.6)$ & $10.5(8.7,12.5)$ & $13.9(11.2,17.1)$ & $10.1(8.6,12.1)$ \\
\hline $2-23$ age in months $(95 \% \mathrm{Cl})$ & $22.8(18.7,27.3)$ & $24.4(20.3,28.6)$ & $28.4(24.3,32.9)$ & $35.8(30.1,42.0)$ & $27.6(24.0,31.9)$ \\
\hline Under 5 years $(95 \% \mathrm{CI})$ & $63.2(55.9,70.0)$ & $65.6(58.9,71.9)$ & $71.5(65.6,77.0)$ & $80.3(73.9,85.8)$ & $70.3(65.0,75.7)$ \\
\hline $\begin{array}{l}\text { Mortality }(95 \% \mathrm{Cl}) ; \boldsymbol{\uparrow} \\
\mathrm{n} / \mathrm{N} \text { (no. of sites) }\end{array}$ & $\begin{array}{l}13.3 \%(5.9,24.6) \\
8 / 60(9)\end{array}$ & $\begin{array}{l}13.8 \%(7.1,23.3) \\
11 / 80(4)\end{array}$ & $\begin{array}{l}13.7 \%(11.4,16.2) \\
115 / 840(17)\end{array}$ & $\begin{array}{l}14.4 \%(7.9,23.4) \\
13 / 90(11)\end{array}$ & $\begin{array}{l}13.7 \%(11.7,15.9) \\
147 / 1070(41)\end{array}$ \\
\hline
\end{tabular}

*Severe malaria anaemia was defined as a composite of $\mathrm{HB}<5 \mathrm{~g} / \mathrm{dl}$ and blood transfusion ordered

१A chi-square test was used to test the equality of case fatality across the transmission categories and the $p$-values are reported in the main text 
areas to 31.1 months $(95 \%$ CI 27.4, 35.1) in areas of highest transmission (Table 1). In the low transmission areas, $74.5 \%$ (95\% CI 68.4, 79.8) of SMA cases were reported below 5 years of age and $88.6 \%$ (95\% CI 84.5, 92.0) in the high transmission areas (Table 1). RD followed a similar age pattern to SMA although children were overall younger in each transmission class, the mean age of RD cases decreased from 40.1 months (95\% CI 35.2, 46.0) in the lowest transmission category to 27.9 months $(95 \%$ CI 24.2, 32.4) in areas of high transmission (Table 1). The mean age in the lowest transmission category for CM was 56.2 months (95\% CI 49.0, $64.9)$ and 39.1 months $(95 \%$ CI 33.9, 45.1) in the highest transmission category. Across all severe phenotypes and all transmission classifications, the majority of admissions continued to occur among children under-5 years (Table 1). Children aged 2-23 months accounted for $30.7 \%$ (95\% CI 26.2, 35.4) of all SMA cases in the low transmission category to $45.9 \%(95 \%$ CI $40.4,51.7)$ in the highest transmission category. Similarly, RD had a higher proportion of cases in the 2-23-month age group in the high transmission setting (50.9\%) compared to the low transmission setting (34.8\%). CM was rarer among children aged 2-23 months in the low transmission setting $(22.8 \%)$ compared to the highest transmission setting (35.8\%) (Table 1).

Among the 52,684 malaria hospitalisations, discharge outcomes were not documented in 2611 (5.0\%) individuals where guardians discharged patients against medical advice, $272(0.5 \%)$ were transferred to another facility and 1431 (2.7\%) where no details were documented. Among 48370 patients where the discharge outcome was documented, 744 (1.6\%) children died. There were differences in case fatalities between transmission settings $(p<0.001)$, ranging from $3.2 \%$ in the lowest transmission category where overall disease burdens were low to $1.0 \%$ in the highest transmission, high burden category (Table 1). In the pooled dataset across all transmission settings, the case fatality for each of the three severe malaria phenotypes was different: SMA (5.1\%: 95\% CI 4.5, 5.8), RD (6.2\%: 95\% CI 5.4, 7.1) and CM (13.7\%: 95\% CI 11.7, 15.9) (Table 1). Although SMA mortality was highest in the two lowest transmission categories (8.3-9.5\%), the case fatality of SMA did not significantly vary across transmission classifications $(p=0.070)$. Similarly, the case fatality for RD was highest in the lowest transmission category (12.9\%) although there were no differences across the four categories of $\mathrm{PfPR}_{2-10}(p=0.076)$. Case fatality for $\mathrm{CM}$ was high (13.3-14.4\%) and similar across all the endemicity classes $(p=0.997)$ (Table 1$)$.

\section{Discussion}

We have analysed the age patterns of malaria hospitalisation in over 52,000 admissions to emergency care wards at 21 hospitals over 49 different site-time-specific periods in East Africa linked to predicted communitybased malaria prevalence. This series represents one of the largest, contemporary descriptions of the epidemiology of severe, hospitalised malaria in Africa. Consistent with earlier descriptions during the 1990s and early 2000s [28-30], the numbers of children admitted with a parasitologically confirmed, primary diagnosis of malaria declines rapidly throughout the first 10 years of life and remains uncommon thereafter (Fig. 1A, B). This agespecific decline in admissions with malaria was broadly similar across all four discrete classes of community prevalence, used to develop sub-national epidemiological stratifications in East Africa. Children admitted with malaria tended to be younger in higher transmission intensity classifications $\left(\geq 10 \% \quad P f R_{2-10}\right)$ compared to those admitted from areas with lower transmission intensity $\left(<10 \% \quad P f R_{2-10}\right) \quad$ (Table 1$)$. Most admissions (69-85\%) across all transmission settings were among children below 5 years of age supporting the current emphasis across SSA of targeting young children for personal protection measures. However, it is important to recognise that when data were corrected for the sampling time-effort to highlight the monthly hospital burdens across transmission sites, malaria admissions are much lower on average in areas of $\mathrm{PfPR}_{2-10} 5-9 \%$ compared to transmission settings where predicted $P f \mathrm{PR}_{2-10}$ is $\geq 10 \%$, and even less common in areas where $P f R_{2-10}$ is $<5 \%$ (Fig. 1A). These findings among a wider range of hospitals, transmission settings, and age inclusion are consistent with our recently published observations based on 6506 malaria hospitalisations among children aged 3 months to 9 years which were restricted to communities immediately proximal to sentinel hospitals [72]. Both data series and analyses highlight that the highest hospital disease burden warranting concerted, high coverage of personal infection prevention strategies remain in areas where $P f \mathrm{PR}_{2-10}$ is $\geq 10 \%$, and hospital disease burdens below this threshold may be less costeffective for sub-national targeting of additional individual-level disease prevention strategies in Africa.

Two individual-level protection strategies that have the potential to augment the current emphasis on vector control in high transmission areas $\left(\mathrm{PfPR}_{2-10} \geq 10 \%\right)$ of East Africa are IPTi and RTS,S/R21 vaccination. Both interventions are aimed at operationally capitalising on successful existing EPI programme strategies (IPTi) or adapted EPI (malaria vaccines). Here we show that malaria hospitalisation among all admissions below 15 years occurring between 2 and 23 months was 34\% in areas where predicted $P f \mathrm{PR}_{2-10}$ was $10-29 \%$ rising to $42 \%$ where predicted $P f \mathrm{PR}_{2-10} \geq 30 \%$. The probability of an admitted child being aged 2-11 months was $13 \%$ rising to $17 \%$ when predicted $P f \mathrm{PR}_{2-10}$ was $10-29 \%$ and $\geq 30 \%$, 
respectively, in support of the approach of targeting young children aged 2-23 months in transmission settings where $P f \mathrm{PR}_{2-10}$ is $\geq 10 \%$. In 2019 , there were $125 /$ 366 (34\%) decentralised administrative areas in East Africa that would benefit from additional personal protection offered through expanded EPI services, where predicted $P f \mathrm{PR}_{2-10}$ was $\geq 10 \%$, covering 2.3 million children aged less than 2 years [64].

Malaria admission above the age of 10 years was relatively uncommon at all transmission sites. There are several, not mutually exclusive, potential explanations as to why malaria hospitalisation becomes uncommon in late childhood across a wide range of transmission intensities. It may be that few parasite exposures result in the development of functional immune response to subsequent malaria hospitalisation [79-81]. Independent of exposure, age per se may confer protection against malaria hospitalisation/severe disease [82] and symptoms may be more easily recognisable among older children able to report symptoms rapidly, increasing opportunities for accessing effective treatment promptly. Whatever the underlying mechanism, our data indicate the rapid decline in severe disease in late childhood and early adolescence. This observation is inconsistent with the modelled global burden of disease estimates of malaria mortality that suggest that $22-58 \%$ of all deaths in SSA occur after the 15th birthday because of poor sensitivity and specificity of VA which these models heavily rely on [83-85].

We view malaria hospitalisation as a severe morbid event, distinct from ambulatory out-patient treatable malaria. Being admitted to a hospital suggests physicians are concerned about outcomes, and an admission leads to collateral consequences for patients' families and the health system. However, a strict definition of severe, lifethreatening malaria encompasses multiple specific pathologies defined for the use of clinical management [15] and outcome analysis during randomised trials [71]. In our series, SMA was the most common of the three severe malaria phenotypes, accounting for $74 \%$ of all severe admissions across all sites and the most frequent syndrome in each of the four transmission intensity classifications (Fig. 3). CM is a much rarer severe disease phenotype, although relatively more important in the lowest transmission settings $\left(P f \mathrm{PR}_{2-10}<5 \%\right)$ (Table 1; Fig. 3). CM tends to present among older children compared to SMA and RD across all transmission settings (Table 1) and the mean age of CM, SMA and RD increases significantly from the highest transmission setting to the lowest, consistent with all-cause malaria hospitalisation (Table 1). We were unable to assess other WHO criteria for severe malaria.

Mortality among malaria hospitalisation in East Africa ranged from $1 \%$ in the high transmission, high admission burden settings, to $3.2 \%$ in the lowest transmission, low admission burden settings (Table 1). Not surprising, the case fatalities were much higher in the severe disease phenotypes: $5.1 \%$ and $6.3 \%$ among the common phenotypes of SMA and RD, respectively, and $13.7 \%$ among the rarer phenotype of CM (Table 1). SMA and RD case fatalities were higher as transmission intensity declined whilst CM case fatality rates were similar, and high, across all transmission classifications (Table 1). Areas that experience low transmission and consequent lower disease burdens may be less well prepared for emergency treatment of severe malaria, and these areas also tend to have more CM than SMA and RD. In-hospital mortality from severe malaria remains high in East Africa and whilst hospital mortality may provide some epidemiological insights into cause-specific mortality burdens in the community [86], they also depend on the quality and timeliness of in-patient emergency care and delay in patient presentation [13].

Unlike our work defining hospital admission rates that purposively chose rural communities within easy reach of the hospital and no competing local admission facilities [72], the present analysis included a much wider community where distance to the hospital and use of other hospitals might have been different between hospital recruitment sites. The influence of travel time, hospital choice, pre-treatment triage at lower-level facilities and the age of hospital admission for malaria remains poorly defined [87]. Here we have presumed equal accessibility for all children aged less than 15 years within each transmission defined location, between sites and with time. To examine the possible influence of access delay, we analysed the duration of fever prior to admission by age and transmission setting, where overall 53\% of all malaria presentations occurred with $48 \mathrm{~h}$ of reported fever onset and no significant differences between age groups or transmission settings (Additional file 1: Fig. S3).

Sites included in this analysis were those with stable perennial transmission in East Africa, as such we did not include traditionally acutely seasonal transmission settings more common in semi-arid areas of West Africa $[29,30,88]$. The influence of seasonal, pulsed parasite exposure on the age-specific patterns of hospitalised malaria might be very different and merits wider investigation in these areas of Africa.

We consider properly resourced, staff training, laboratory support and electronic data capture tools as essential to defining the clinical epidemiology of severe malaria and may serve as barometers of communitylevel transmission intensity to target interventions and ultimately used to monitor impact [28, 38, 86, 89]. We have shown that hospital burdens and age at admission scale with increasing levels of community-based parasite 
transmission intensity. We have defaulted to using classifications of community prevalence used by national programmes to provide information on targeting intervention combinations for prevention. With adequate resources, hospital surveillance alone could be used to decide on maximising age targets for intervention, circumventing the need for complex modelled predictions of community parasite prevalence. Decisions on the implementation of new malaria strategies must be tailored to the local health systems and epidemiological context. Investing in sentinel hospital surveillance would be an important layer of data to consider in all future subnational, intervention stratification.

\section{Conclusion}

Targeting chemoprevention or vaccination programmes to areas where community-based parasite prevalence is $\geq 10 \%$ is likely to cover the highest hospital burden. Extending chemoprevention e.g intermittent presumptive treatment in infancy to children aged 2-23 months and current vaccine age eligibility would target the most vulnerable age groups for malaria hospitalisation and the dominant severe disease phenotype of SMA.

\section{Abbreviations}

AVPU: Alert, response to voice, response to pain, or unconscious:

BCS: Blantyre Coma Score; CM: Cerebral malaria; EPI: Expanded programme of immunisation; GLMM: Generalised linear mixed model; HB: Haemoglobin IPTi: Intermittent presumptive treatment in infancy; PfPR ${ }_{2-10}$ : Plasmodium falciparum parasite prevalence in children aged 2-10 years; RD: Respiratory distress; RDT: Rapid diagnostic tests; SMA: Severe malaria anaemia; SMC: Seasonal malaria chemoprevention; SSA: Sub-Saharan Africa; VA: Verbal autopsies; WAIC: Widely applicable information criterion

\section{Supplementary Information}

The online version contains supplementary material available at https://doi. org/10.1186/s12916-021-02224-w.

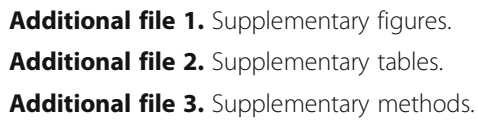

\section{Acknowledgements}

The authors are grateful to the many people who have supported the clinical surveillance in the respective sites over the last 15 years, notably at Kilifi, Kenya (Patricia Njuguna, Amek Nyaguara, Caroline Ngetsa, Kennedy Awuondo, Gabriel Mwambingu, Charles Newton, Jay Berkeley, Kath Maitland); Busia, Bungoma, Homa Bay, Kakamega, Kisumu, Kitale, Migori and Vihiga hospitals that form part of the Clinical Information Network (CIN) (Mike English, Fred Were, Philip Ayieko, Grace Irimu, Jalemba Aluvaala, Lynda Isaaka, Mercy Chepkirui, George Mbevi in collaboration with the Ministry of Health); Siaya, Kenya (Sammy Khagayi, Christopher Odera, Rob Brieman, Danny Feikin, Aaron Samuels); Rarieda, Kenya (Patrick Munywoki, Joshua Auko, George Aol, Rob Brieman, Danny Feikin); sites in Uganda (Moses Kamya, Grant Dorsey, Mohamed Lamorde); Bagamoyo, Tanzania (Omar Ali Juma, Ummi Abdul); and Muheza, Tanzania (Frank Mtei, Behzad Nadjm, Ben Amos). We also acknowledge those in the KEMRI-Wellcome Trust programme who helped in address location work to administrative areas and map production (David Kyalo, Laurissa Suiyanka, Samuel Muchiri) and Emelda Okiro for comments on an earlier draft of the manuscript.

\section{Authors' contributions}

RWS and AK conceived the study. AK and RSP analysed and interpreted the data with inputs from SG, JL, PB and RWS. SA, AM, CK, MO, AA1, NM, SM, GB, $A A 2, J K, A S, J F N, S K, N A O, B O N, A O, N S, T A, S A, A F M, G M, H R$ and PB managed the paediatric ward surveillance in respective sites. EM helped in the geographical matching of admission residential addresses. VAA performed model prediction of parasite prevalence. AK, RSP and RWS wrote the first draft of the paper and the supplementary materials. All authors critically revised successive drafts of the paper and approved the final version, as submitted.

\section{Funding}

This work was supported through support to RWS as part of his Wellcome Trust Principal Research Fellowships (212176) that also provides support for AK, EM and RSP. VAA is funded as a Wellcome Trust Training Fellow (211208). Surveillance at Busia, Bungoma, Homa Bay, Kakamega, Kisumu, Kitale, Migori and Vihiga surveillance has been supported by funds from the Wellcome Trust (097170 and 207522) awarded to Professor Mike English under his Senior Fellowship and the Kenya Major Overseas Programme, Wellcome Trust core grant (092654). CIN is partly supported by an award to AA from the FCDO/MRC/NIHR/Wellcome Trust Joint Global Health Trials Scheme (MR/R006083/1) and the CDC Foundation, through funding from the World Health Organization for the RTS,S evaluation (Project requisition number 2018/854999) that also supports SA. Surveillance at the Kilifi site has been supported by the Wellcome Trust since 2006 under core award for the East African Major Overseas Programme (077092, 092654 and 203077).

Surveillance at Siaya was supported by core funding provided by Centers for Disease Control and Prevention (cooperative agreement number

5U01GH000048). Surveillance at Rarieda was supported from core funding of the International Emerging Infections Program and Global Disease Detection Division of the US Centers for Disease Control and Prevention. Hospital surveillance in Uganda has been supported by the President's Malaria, US Agency for International Development, under the terms of an Interagency Agreement with the Centres for Disease Control and Prevention (cooperative agreement numbers: 1U51CK000117 and 5NU2GGH001744-02-00). Surveillance at Handeni, Mkinga and Muheza was supported by core funding provided by European Commission (Europaid) (SANTE/2004/078-607).

Surveillance at Bagamoyo was supported by the PATH Malaria Vaccine Initiative (RTS,S ClinicalTrials.gov number, NCT00866619) and Ifakara Health Institute. Authors affiliated with the KEMRI-Wellcome Trust Programme in Kenya are grateful for the support of the Wellcome Trust to the core award for the East African Major Overseas Programme (203077). CM, SK, BON and NAO are grateful for continued support from KEMRI. JL was supported by a research lectureship by the Department of Zoology, University of Oxford.

\section{Availability of data and materials}

Data used in this analysis have been curated and uploaded to the Harvard Dataverse [90]. Correspondence and requests for materials should be addressed to the KEMRI Wellcome Data Governance Committee (dgc@kemriwellcome.org). These data are available through a formal requesting process to the KEMRI Institutional Data Access/Ethics Committee. Guideline details can be found on the KEMRI Wellcome website (https://kemri-wellcome.org/ aboutus/\#ChildVerticalTab_15).

\section{Declarations}

\section{Ethics approval and consent to participate}

Kilifi North and South: Kenya Medical Research Institute/Scientific and Ethics Review Unit (KEMRI SERU) IRB numbers 1433, 3057, 3149; Busia, Bungoma, Homa Bay, Kakamega, Kisumu, Kitale, Migori and Vihiga: KEMRI SERU IRB numbers 3459/3852 and MoH approval PPB/ECCT/19/06/03/2019(128); Siaya: KEMRI SERU IRB numbers 1801/2558; CDC Atlanta approvals 3308/6543: Rarieda: KEMRI SERU IRB numbers 932/1899 and CDC Atlanta approval 4566; Jinja, Tororo, Apac, Arua, Mubende, Kambuga and Kabale: surveillance included the collection of routine hospital data approved as public health surveillance/non-research by CDC (NCEZID \#031416), and approved by the Director General of Health Services, Ministry of Health, Uganda; Handeni, Mkinga and Muheza: The study was approved by the ethics committees of the National Institute for Medical Research, Tanzania, and the London School of Hygiene and Tropical Medicine; Bagamoyo: The study was approved by 
National Institute for Medical Research, Tanzania, Ethics Committee of the Swiss Tropical Institute and Ifakara Health Institute ethics committees.

\section{Consent for publication}

Not applicable.

\section{Competing interests}

The authors declare that they have no competing interests.

\section{Author details}

${ }^{1}$ Kenya Medical Research Institute (KEMRI) - Wellcome Trust Research Programme, Nairobi, Kenya. ${ }^{2}$ Department of Zoology, University of Oxford, Oxford, UK. ${ }^{3}$ Child Health and Development Centre, College of Health Sciences, Makerere University, Kampala, Uganda. ${ }^{4}$ Kenya Medical Research Institute (KEMRI) - Wellcome Trust Research Programme, Kilifi, Kenya. ${ }^{5}$ Kenya Medical Research Institute (KEMRI), Centre for Global Health Research, Kisumu, Kenya. ${ }^{6}$ Infectious Diseases Research Collaboration, Kampala, Uganda. ${ }^{7}$ Ifakara Health Institute, Bagamoyo, Tanzania. ${ }^{8}$ Kilimanjaro Christian Medical Centre/Joint Malaria Programme, Moshi, Tanzania. ${ }^{9}$ London School of Hygiene and Tropical Medicine, London, UK. ${ }^{10}$ National Institute for Medical Research, Amani Research Centre, Muheza, Tanzania. ${ }^{11}$ Centre for Tropical Medicine and Global Health, Nuffield Department of Clinical Medicine, University of Oxford, Oxford, UK.

\section{Received: 8 October 2021 Accepted: 21 December 2021}

\section{Published online: 27 January 2022}

\section{References}

1. Greenwood BM, Marsh K, Snow RW. Why do some African children develop severe malaria? Parasitol Today. 1991;7(10):277-81. https://doi.org/10.1016/ 0169-4758(91)90096-7.

2. White N, Pukrittayakamee S, Hien T, Faiz M, Mokuolu O, Dondorp A. Malaria. Lancet. 2014;383(9918):723-35. https://doi.org/10.1016/S0140-6736(13 60024-0.

3. Doolan DL, Dobaño C, Baird JK. Acquired immunity to malaria. Clin Microbiol Rev. 2009;22(1):13-36. https://doi.org/10.1128/CMR.00025-08.

4. White M, Watson J. Malaria: age, exposure and immunity. Elife. 2018;7: e40150. https://doi.org/10.7554/eLife.40150.

5. Greenwood BM. The epidemiology of malaria. Ann Trop Med Parasitol. 1997;91(7):763-9. https://doi.org/10.1080/00034983.1997.11813201.

6. Langhorne J, Ndungu FM, Sponaas A-M, Marsh K. Immunity to malaria: more questions than answers. Nat Immunol. 2008;9(7):725-32. https://doi. org/10.1038/ni.f.205.

7. Snow RW. Sixty years trying to define the malaria burden in Africa: have we made any progress? BMC Med. 2014;12(1):227. https://doi.org/10.1186/s1291 6-014-0227-x.

8. WHO. Verbal autopsy standards: ascertaining and attributing causes of death. In: The 2012 WHO verbal autopsy instrument. Geneva: World Health Organization; 2012. http://www.who.int/healthinfo/statistics/verbala utopsystandards/en/index2.html. Accessed 01 Oct 2019.

9. Snow RW, Marsh K. How useful are verbal autopsies to estimate childhood causes of death? Health Policy Plan. 1992;7(1):22-9. https://doi.org/10.1093/ heapol/7.1.22

10. Anker M. The effect of misclassification error on reported cause-specific mortality fractions from verbal autopsy. Int J Epidemiol. 1997;26(5):1090-6. https://doi.org/10.1093/ije/26.5.1090.

11. Mpimbaza A, Filler S, Katureebe A, Kinara SO, Nzabandora E, Quick L, et al. Validity of verbal autopsy procedures for determining malaria deaths in different epidemiological settings in Uganda. PLoS One. 2011;6(10):e26892. https://doi.org/10.1371/journal.pone.0026892.

12. Mackintosh $\mathrm{CL}$, Beeson JG, Marsh K. Clinical features and pathogenesis of severe malaria. Trends Parasitol. 2004;20(12):597-603. https://doi.org/10.101 6/j.pt.2004.09.006

13. Maitland K. Management of severe paediatric malaria in resource-limited settings. BMC Med. 2015;13(1):42. https://doi.org/10.1186/s12916-014-0263-6

14. Manning L, Laman M, Davis WA, Davis TM. Clinical features and outcome in children with severe Plasmodium falciparum malaria: a meta-analysis. PLoS One. 2014;9(2):e86737. https://doi.org/10.1371/journal.pone.0086737.

15. WHO. Severe malaria. Trop Med Int Health. 2014;19(Suppl 1):7-131.

16. WHO, RBM Partnership to End Malaria. High burden to high impact: a targeted malaria response. Geneva: World Health Organization; 2018.
https://apps.who.int/iris/bitstream/handle/10665/275868/WHO-CDS-GMP-2 018.25-eng.pdf?ua=1. Accessed 12 Jan 2020

17. Snow RW, Sartorius B, Kyalo D, Maina J, Amratia P, Mundia CW, et al. The prevalence of Plasmodium falciparum in sub-Saharan Africa since 1900. Nature. 2017;550(7677):515-8. https://doi.org/10.1038/nature24059.

18. Metselaar D, Van Thiel P. Classification of malaria. Trop Geogr Med. 1959;11: 157-61.

19. Smith DL, Guerra CA, Snow RW, Hay SI. Standardizing estimates of the Plasmodium falciparum parasite rate. Malar J. 2007;6(1):131. https://doi.org/1 $0.1186 / 1475-2875-6-131$

20. Issifou S, Kendjo E, Missinou MA, Matsiegui PB, Dzeing-Ella A, Dissanami FA, et al. Differences in presentation of severe malaria in urban and rural Gabon. Am J Trop Med Hyg. 2007;77(6):1015-9. https://doi.org/10.4269/a jtmh.2007.77.1015

21. Snow RW, De Azevedo IB, Lowe B, Kabiru E, Nevill C, Mwankusye S, et al. Severe childhood malaria in two areas of markedly different falciparum transmission in east Africa. Acta Trop. 1994;57(4):289-300. https://doi.org/1 0.1016/0001-706X(94)90074-4.

22. Slutsker L, Taylor TE, Wirima JJ, Steketee RW. In-hospital morbidity and mortality due to malaria-associated severe anaemia in two areas of Malawi with different patterns of malaria infection. Trans R Soc Trop Med Hyg. 1994;88(5):548-51. https://doi.org/10.1016/0035-9203(94)90157-0.

23. Modiano D, Sirima B, Sawadogo A, Sanou I, Pare J, Konate A, et al. Severe malaria in Burkina Faso: urban and rural environment. Parassitologia. 1999; 41(1-3):251-4

24. Snow RW, Omumbo JA, Lowe B, Molyneux CS, Obiero J-O, Palmer A, et al. Relation between severe malaria morbidity in children and level of Plasmodium falciparum transmission in Africa. Lancet. 1997;349(9066):16504. https://doi.org/10.1016/S0140-6736(97)02038-2.

25. Snow RW, Marsh K. The consequences of reducing transmission of Plasmodium falciparum in Africa. Adv Parasitol. 2002;52:235-64. https://doi. org/10.1016/S0065-308X(02)52013-3.

26. Idro R, Aloyo J, Mayende L, Bitarakwate E, John C, Kivumbi G. Severe malaria in children in areas with low, moderate and high transmission intensity in Uganda. Trop Med Int Health. 2006;11(1):115-24. https://doi.org/10.1111/j.13 65-3156.2005.01518.x.

27. Reyburn H, Mbatia R, Drakeley C, Bruce J, Carneiro I, Olomi R, et al. Association of transmission intensity and age with clinical manifestations and case fatality of severe Plasmodium falciparum malaria. JAMA. 2005; 293(12):1461-70. https://doi.org/10.1001/jama.293.12.1461.

28. Okiro EA, Al-Taiar A, Reyburn H, Idro R, Berkley JA, Snow RW. Age patterns of severe paediatric malaria and their relationship to Plasmodium falciparum transmission intensity. Malar J. 2009;8(1):4. https://doi.org/10.1186/1475-2 875-8-4.

29. Carneiro I, Roca-Feltrer A, Griffin JT, Smith L, Tanner M, Schellenberg JA, et al. Age-patterns of malaria vary with severity, transmission intensity and seasonality in sub-Saharan Africa: a systematic review and pooled analysis. PLoS One. 2010;5(2):e8988. https://doi.org/10.1371/journal.pone.0008988.

30. Roca-Feltrer A, Carneiro I, Smith L, Schellenberg JRA, Greenwood B, Schellenberg $D$. The age patterns of severe malaria syndromes in subSaharan Africa across a range of transmission intensities and seasonality settings. Malar J. 2010;9(1):282. https://doi.org/10.1186/1475-2875-9-282.

31. Griffin JT, Ferguson NM, Ghani AC. Estimates of the changing age-burden of Plasmodium falciparum malaria disease in sub-Saharan Africa. Nat Commun. 2014:5(1):3136. https://doi.org/10.1038/ncomms4136.

32. Smith T, Ross A, Maire N, Chitnis N, Studer A, Hardy D, et al. Ensemble modeling of the likely public health impact of a pre-erythrocytic malaria vaccine. PLoS Med. 2012;9(1):e1001157. https://doi.org/10.1371/journal. pmed. 1001157.

33. Penny MA, Verity R, Bever CA, Sauboin C, Galactionova K, Flasche S, et al. Public health impact and cost-effectiveness of the RTS, S/AS01 malaria vaccine: a systematic comparison of predictions from four mathematical models. Lancet. 2016;387(10016):367-75. https://doi.org/10.1016/S0140-673 6(15)00725-4.

34. Walker PG, Griffin JT, Ferguson NM, Ghani AC. Estimating the most efficient allocation of interventions to achieve reductions in Plasmodium falciparum malaria burden and transmission in Africa: a modelling study. Lancet Glob Health. 2016:4(7):e474-e84. https://doi.org/10.1016/S2214-109X(16)30073-0.

35. Reiker T, Golumbeanu M, Shattock A, Burgert L, Smith TA, Filippi S, et al. Emulator-based Bayesian optimization for efficient multi-objective calibration of an individual-based model of malaria. medRxiv. 2021; www. 
medrxiv.org/content/10.1101/2021.01.27.21250484v4.full. Accessed 15 Aug 2021.

36. WHO. Intermittent preventive treatment for infants using sulfadoxinepyrimethamine (SP-IPTi) for malaria control in Africa: implementation field guide. Geneva: World Health Organization; 2011. http://apps.who.int/iris/ bitstream/handle/10665/70736/WHO_IVB_11.07_eng.pdf. Accessed 05 May 2021

37. Esu EB, Oringanje C, Meremikwu MM. Intermittent preventive treatment for malaria in infants. Cochrane Database Syst Rev. 2021;2:12.

38. RTS,S Clinical Trials Partnership. Efficacy and safety of RTS, S/AS01 malaria vaccine with or without a booster dose in infants and children in Africa: final results of a phase 3, individually randomised, controlled trial. Lancet. 2015;386:31-45

39. WHO. Malaria vaccine background paper for SAGE. Geneva: World Health Organization; 2015. https://www.who.int/immunization/sage/meetings/201 5/october/1_Final_malaria_vaccine_background_paper_v2015_09_30.pdf. Accessed 19 Aug 2021

40. Datoo MS, Natama MH, Somé A, Traoré O, Rouamba T, Bellamy D, et al. Efficacy of a low-dose candidate malaria vaccine, R21 in adjuvant Matrix-M, with seasonal administration to children in Burkina Faso: a randomised controlled trial. Lancet. 2021;397(10287):1809-18. https://doi.org/10.1016/ S0140-6736(21)00943-0

41. WHO. Seasonal malaria chemoprevention with sulfadoxine-pyrimethamine plus amodiaquine in children: a field guide. Geneva: World Health Organization; 2013. https://apps.who.int/iris/bitstream/handle/10665/85726/ 9789241504737_eng.pdf. Accessed 07 Jun 2021

42. Greenwood BM, Dicko A, Sagara I, Zongo I, Tinto H, Cairns M, et al. Seasonal vaccination against malaria: a potential use for an imperfect malaria vaccine. Malar J. 2017;16(1):182. https://doi.org/10.1186/s12936-017-1841-9.

43. Chandramohan D, Zongo I, Sagara I, Cairns M, Yerbanga R-S, Diarra M, et al. Seasonal malaria vaccination with or without seasonal malaria chemoprevention. N Engl J Med. 2021;385(11):1005-17. https://doi.org/10.1 056/NEJMoa2026330

44. Kenya RTS,S. Unpublished data from admissions resident in non-RTS,S pilot implementation sub-counties or those serving as control sub-counties. 2021.

45. Akech S, Chepkirui M, Ogero M, Agweyu A, Irimu G, English M, et al. The clinical profile of severe pediatric malaria in an area targeted for routine RTS,S/AS01 malaria vaccination in Western Kenya. Clin Infect Dis. 2020;71(2): 372-80. https://doi.org/10.1093/cid/ciz844.

46. Amboko Bl, Ayieko P, Ogero M, Julius T, Irimu G, English M, et al. Malaria investigation and treatment of children admitted to county hospitals in western Kenya. Malar J. 2016;15(1):506. https://doi.org/10.1186/s12936-016-1 553-6.

47. Ayieko P, Ogero M, Makone B, Julius T, Mbevi G, Nyachiro W, et al. Characteristics of admissions and variations in the use of basic investigations, treatments and outcomes in Kenyan hospitals within a new Clinical Information Network. Arch Dis Child. 2016;101(3):223-9. https://doi. org/10.1136/archdischild-2015-309269.

48. Mogeni P, Williams TN, Fegan G, Nyundo C, Bauni E, Mwai K, et al. Age, spatial, and temporal variations in hospital admissions with malaria in Kilifi County, Kenya: a 25-year longitudinal observational study. PLoS Med. 2016; 13(6):e1002047. https://doi.org/10.1371/journal.pmed.1002047.

49. Njuguna P, Maitland K, Nyaguara A, Mwanga D, Mogeni P, Mturi N, et al. Observational study: 27 years of severe malaria surveillance in Kilifi. Kenya BMC Med. 2019;17(1):124. https://doi.org/10.1186/s12916-019-1359-9.

50. Kamau A, Mtanje G, Mataza C, Mwambingu G, Mturi N, Mohammed S, et al. Malaria infection, disease and mortality among children and adults on the coast of Kenya. Malaria J. 2020;19(1):210. https://doi.org/10.1186/s12936-02003286-6.

51. Nyawanda BO, Mott JA, Njuguna HN, Mayieka L, Khagayi S, Onkoba R, et al. Evaluation of case definitions to detect respiratory syncytial virus infection in hospitalized children below 5 years in Rural Western Kenya, 2009-2013. BMC Infect Dis. 2016;16(1):218. https://doi.org/10.1186/s12879-016-1532-0.

52. Achieng AO, Hengartner NW, Raballah E, Cheng Q, Anyona SB, Lauve N, et al. Integrated OMICS platforms identify LAIR1 genetic variants as novel predictors of cross-sectional and longitudinal susceptibility to severe malaria and all-cause mortality in Kenyan children. EBioMedicine. 2019;45:290-302. https://doi.org/10.1016/j.ebiom.2019.06.043.

53. Bigogo G, Audi A, Aura B, Aol G, Breiman RF, Feikin DR. Health-seeking patterns among participants of population-based morbidity surveillance in rural western Kenya: implications for calculating disease rates. Int I Infect Dis. 2010;14(11):e967-e73. https://doi.org/10.1016/j.jiid.2010.05.016.

54. Feikin DR, Njenga MK, Bigogo G, Aura B, Aol G, Audi A, et al. Viral and bacterial causes of severe acute respiratory illness among children aged less than 5 years in a high malaria prevalence area of western Kenya, 2007-2010. Pediatr Infect Dis J. 2013;32(1):e14-e9. https://doi.org/10.1097/INF.0b013e31 $826 f d 39 b$.

55. Mpimbaza A, Sears D, Sserwanga A, Kigozi R, Rubahika D, Nadler A, et al. Admission risk score to predict inpatient pediatric mortality at four public hospitals in Uganda. PLoS One. 2015;10(7):e0133950. https://doi.org/10.13 71/journal.pone.0133950.

56. Mpimbaza A, Walemwa R, Kapisi J, Sserwanga A, Namuganga JF, Kisambira $Y$, et al. The age-specific incidence of hospitalized paediatric malaria in Uganda. BMC Infect Dis. 2020;20(1):503. https://doi.org/10.1186/s12879-02005215-z.

57. Appiah GD, Mpimbaza A, Lamorde M, Freeman M, Kajumbula H, Salah Z, et al. Salmonella bloodstream infections in hospitalized children with acute febrile illness-Uganda, 2016-2019. Am J Trop Med Hyg. 2021;201453(1):3746. https://doi.org/10.4269/ajtmh.20-1453.

58. Mpimbaza A, Sserwanga A, Rutazaana D, Kapisi J, Walemwa R, Suiyanka L, et al. Changing malaria fever test positivity among paediatric admissions to Tororo district hospital, Uganda 2012-2019. Malaria J. 2020;19(1):1-11. https://doi.org/10.1186/s12936-020-03490-4.

59. Mwangoka GW, Burgess B, Aebi T, Sasi P, Abdulla S. The Ifakara Health Institute's Bagamoyo Research and Training Centre: a well-established clinical trials site in Tanzania. Int Health. 2009;1(1):85-90. https://doi.org/10.1 016/j.inhe.2009.06.009.

60. RTS,S Clinical Trials Partnership. A phase 3 trial of RTS, S/AS01 malaria vaccine in African infants. N Engl J Med. 2012;367:2284-95.

61. JDA W, Smithson P, Hildon Z. Comparing changes in morbidity and mortality in under-five year olds in Kilombero and Bagamoyo district hospitals. Ifakara Health Institute; 2014. https://core.ac.uk/download/pdf/1 6666681.pdf. Accessed 05 Aug 2021.

62. Nadjm B, Amos B, Mtove G, Ostermann J, Chonya S, Wangai H, et al. WHO guidelines for antimicrobial treatment in children admitted to hospital in an area of intense Plasmodium falciparum transmission: prospective study. BMJ. 2010;340(mar30 1):c1350. https://doi.org/10.1136/bmj.c1350.

63. Nadjm B, Mtove G, Amos B, Hildenwall H, Najjuka A, Mtei F, et al. Blood glucose as a predictor of mortality in children admitted to the hospital with febrile illness in Tanzania. Am J Trop Med Hyg. 2013;89(2):232-7. https://doi. org/10.4269/ajtmh.13-0016

64. Alegana VA, Macharia PM, Muchiri S, Mumo E, Oyugi E, Kamau A, et al. Plasmodium falciparum parasite prevalence in East Africa: updating data for malaria stratification. PLOS Global Public Health. 2021;1(12):e0000014. https://doi.org/10.1371/journal.pgph.0000014.

65. Macharia PM, Giorgi E, Noor AM, Waqo E, Kiptui R, Okiro EA, et al. Spatiotemporal analysis of Plasmodium falciparum prevalence to understand the past and chart the future of malaria control in Kenya. Malar J. 2018;17(1): 340. https://doi.org/10.1186/s12936-018-2489-9.

66. Runge M, Snow RW, Molteni F, Thawer S, Mohamed A, Mandike R, et al. Simulating the council-specific impact of anti-malaria interventions: a tool to support malaria strategic planning in Tanzania. PLoS One. 2020;15(2): e0228469. https://doi.org/10.1371/journal.pone.0228469.

67. Mappin B, Cameron E, Dalrymple U, Weiss DJ, Bisanzio D, Bhatt S, et al. Standardizing Plasmodium falciparum infection prevalence measured via microscopy versus rapid diagnostic test. Malar J. 2015;14(1):460. https://doi. org/10.1186/s12936-015-0984-9.

68. Runge M, Molteni F, Mandike R, Snow RW, Lengeler C, Mohamed A, et al. Applied mathematical modelling to inform national malaria policies, strategies and operations in Tanzania. Malar J. 2020;19(1):101. https://doi. org/10.1186/s12936-020-03173-0.

69. Thawer SG, Chacky F, Runge M, Reaves E, Mandike R, Lazaro S, et al. Subnational stratification of malaria risk in mainland Tanzania: a simplified assembly of survey and routine data. Malar J. 2020;19(1):177. https://doi. org/10.1186/s12936-020-03250-4.

70. Marsh K, Forster D, Waruiru C, Mwangi I, Winstanley M, Marsh V, et al. Indicators of life-threatening malaria in African children. N Engl J Med. 1995; 332(21):1399-404. https://doi.org/10.1056/NEJM199505253322102.

71. Bejon P, Berkley JA, Mwangi T, Ogada E, Mwangi I, Maitland K, et al. Defining childhood severe falciparum malaria for intervention studies. PLoS Med. 2007;4(8):e251. https://doi.org/10.1371/journal.pmed.0040251. 
72. Paton RS, Kamau A, Akech S, Agweyu A, Ogero M, Mwandawiro C, et al. Malaria infection and severe disease risks in Africa. Science. 2021;373(6557): 926-31. https://doi.org/10.1126/science.abj0089.

73. Watanabe S, Opper M. Asymptotic equivalence of Bayes cross validation and widely applicable information criterion in singular learning theory. J Mach Learn Res. 2010;11:3571-94.

74. Stan Development Team. Stan modeling language users guide and reference manual. 2021. https://mc-stan.org. Accessed 15 Sep 2021.

75. R Core Team. R: a language and environment for statistical computing 2020. www.R-project.org/. Accessed 05 Sep 2021.

76. WHO. RTS,S malaria vaccine reaches more than 650000 children in Ghana, Kenya and Malawi through groundbreaking pilot programme. Geneva: World Health Organization; 2021. https://www.who.int/news/item/20-04-2021-rts-smalaria-vaccine-reaches-more-than-650-000-children-in-ghana-kenya-and-mala wi-through-groundbreaking-pilot-programme. Accessed 28 Aug 2021

77. Grobusch MP, Lell B, Schwarz NG, Gabor J, Dörnemann J, Pötschke M, et al. Intermittent preventive treatment against malaria in infants in Gabon-a randomized, double-blind, placebo-controlled trial. J Infect Dis. 2007;196(11): 1595-602. https://doi.org/10.1086/522160.

78. Bigira V, Kapisi J, Clark TD, Kinara S, Mwangwa F, Muhindo MK, et al. Protective efficacy and safety of three antimalarial regimens for the prevention of malaria in young Ugandan children: a randomized controlled trial. PLoS Med. 2014; 11(8):e1001689. https://doi.org/10.1371/journal.pmed.1001689.

79. Gupta S, Hill A, Kwiatkowski D, Greenwood AM, Greenwood BM, Day KP. Parasite virulence and disease patterns in Plasmodium falciparum malaria. Proc Natl Acad Sci U S A. 1994;91(9):3715-9. https://doi.org/10.1073/pnas.91. 9.3715 .

80. Gupta S, Snow RW, Donnelly C, Newbold C. Acquired immunity and postnatal clinical protection in childhood cerebral malaria. Proc R Soc Lond B. 1999;266(1414):33-8. https://doi.org/10.1098/rspb.1999.0600.

81. Gupta S, Snow RW, Donnelly CA, Marsh K, Newbold C. Immunity to noncerebral severe malaria is acquired after one or two infections. Nat Med. 1999;5(3):340-3. https://doi.org/10.1038/6560.

82. Baird JK, Masbar S, Basri H, Tirtokusumo S, Subianto B, Hoffman SL. Agedependent susceptibility to severe disease with primary exposure to Plasmodium falciparum. J Infect Dis. 1998;178(2):592-5. https://doi.org/10.1 086/517482

83. Gething PW, Casey DC, Weiss DJ, Bisanzio D, Bhatt S, Cameron E, et al. Mapping Plasmodium falciparum mortality in Africa between 1990 and 2015. N Engl J Med. 2016;375(25):2435-45. https://doi.org/10.1056/NEJMoa1 606701.

84. Murray CJ, Ortblad KF, Guinovart C, Lim SS, Wolock TM, Roberts DA, et al. Global, regional, and national incidence and mortality for HIV, tuberculosis, and malaria during 1990-2013: a systematic analysis for the Global Burden of Disease Study 2013. Lancet. 2014;384(9947):1005-70. https://doi.org/10.1 016/50140-6736(14)60844-8.

85. Murray CJ, Rosenfeld LC, Lim SS, Andrews KG, Foreman KJ, Haring D, et al. Global malaria mortality between 1980 and 2010: a systematic analysis. Lancet. 2012;379(9814):413-31. https://doi.org/10.1016/S0140-6736(12 60034-8.

86. English M, Mwaniki P, Julius T, Chepkirui M, Gathara D, Ouma PO, et al. Hospital mortality-a neglected but rich source of information supporting the transition to higher quality health systems in low and middle income countries. BMC Med. 2018;16(1):32. https://doi.org/10.1186/s12916-018-1024-8.

87. Mousa A, Al-Taiar A, Anstey NM, Badaut C, Barber BE, Bassat Q, et al. The impact of delayed treatment of uncomplicated $P$. falciparum malaria on progression to severe malaria: a systematic review and a pooled multicentre individual-patient meta-analysis. PLoS Med. 2020;17(10):e1003359.

88. Cairns M, Roca-Feltrer A, Garske T, Wilson AL, Diallo D, Milligan PJ, et al. Estimating the potential public health impact of seasonal malaria chemoprevention in African children. Nat Commun. 2012;3(1):881. https:// doi.org/10.1038/ncomms 1879 .

89. Taylor T, Slutsker L. Tracking severe malaria disease. Science. 2021;373(6557): 855-6. https://doi.org/10.1126/science.abk3443.

90. Kamau A, Paton RS, Akech S, Mpimbaza A, Khazenzi C. M O. Replication data for: Malaria hospitalisation in East Africa: age, phenotype and transmission intensity: Harvard Dataverse; 2021. https://doi.org/10.7910/DVN/CFYACQ.

\section{Publisher's Note}

Springer Nature remains neutral with regard to jurisdictional claims in published maps and institutional affiliations.

\section{Ready to submit your research? Choose BMC and benefit from:}

- fast, convenient online submission

- thorough peer review by experienced researchers in your field

- rapid publication on acceptance

- support for research data, including large and complex data types

- gold Open Access which fosters wider collaboration and increased citations

- maximum visibility for your research: over $100 \mathrm{M}$ website views per year

At BMC, research is always in progress.

Learn more biomedcentral.com/submissions 